\title{
PROSPECTS FOR AGRICULTURAL BUSINESS DEVELOPMENT IN IMERETI REGION
}

\section{GODERDZI SHANIDZE}

Akaki Tsereteli State University, Georgia

goderdzi.shanidze@atsu.edu.ge

Abstract. The development of agribusiness in Georgia is quite promising and realistic. Imereti region is one of the most distinguished regions in Georgia in terms of agricultural production. Imereti region has been involved in the production and sales of agricultural products for a long time (e.g. grapes, tea, cheese, herbs, cucumbers, tomatoes, etc.) that have been widely popular throughout the country.

The research has shown that various products produced in Imereti region (especially: cucumbers, tomatoes, herbs, wine, cheese, tea) are quite in demand in the hotel food service, however, there is still no adequate supply of hotels with the products produced in Imereti region.

\section{KEYWORDS: AGRIBUSINESS, IMERETI REGION, HOTEL, TOURISTS, FARMERS.}

For citation: Shanidze, G. (2020). Prospects for Agricultural Business Development in Imereti Region. Globalization and Business №10, 248-251. https://doi.org/10.35945/gb.2020.10.032

\section{REVIEW OF LITERATURE:}

1. Tokmazishvili M.; «Theoretical Dilemma of Agrarian Relations». Collection of scientific works of Tbilisi Open University, Tbilisi, 2018. This work is focused on the fact that today Georgia actually consumes more imported food than it produces. Questions arise about the place of the agricultural industry in the sectoral structure of Georgia, whether it is worth focusing on policy, recognizing agriculture as a priority sector.

2. Koguashvili P.; «Protecting food security is the primary duty of the government», Scientific-Information Magazine «New Agrarian Georgia» Tbilisi 2013. № 12 (32) This work states that ensuring food security is the first of the problems to be solved in Georgia in the near future. It considers the countryss ability to provide its own population with basic food products at the expense of the production of local resources.

3. "Georgiass economic development priorities». Regional Development Program (GARF-RD) Policy Papers №2, Tbilisi 2016. pp. 58-60. In this work it is noted that the state should minimally interfere in entrepreneurial activities and not compete with the private sector. Regional development is seen as the most important factor in achieving overall national success.

4. Thomas P. Zacharias; „Modeling and Simulating Price, Yield, and Production Distributions for Risk Analysis in Agriculture: Discussion", Materials of Cambridge University. 2015. The purpose of this session is to discuss various procedures for modeling agricultural price and yield distributions. The model results are then used to provide improved analyses for agricultural risk management with the focus primarily upon the agricultural production sector

5. Jeffrey M. Gillespie, Bampasidou M.; "Designing agricultural economics and agribusiness undergraduate programs" Materials of Cambridge University. 2018. The work suggests that the farmerss share of the market basket provides a means to illustrate the importance of post-farm gate agricultural business in converting raw agricultural commodities to products consumers may purchase in the grocery store. In 2015, the farmerss share of the market basket for food items averaged 16\% (USDA, Economic Research Service, 2016), suggesting that \$0.84 of every dollar spent for these food products went to post-farm gate agricultural enterprises.

\section{INTRODUCTION}

The development of agribusiness in Georgia is quite promising and realistic. Imereti region is one of the most distinguished regions in Georgia in terms of agricultural production. Imereti region has been involved in the production and sales of agricultural products for a long time (e.g. grapes, tea, cheese, herbs, cucumbers, tomatoes, etc.) that have been widely popular throughout the country.

Recently, there has been an increased import of agricultural products from foreign countries to Georgia. The question naturally arises as to whether it is necessary to bring the products into the country produced by the local farming industry? This does not mean supporting protectionist policies and denying competition, but it is necessary to define 
how possible it is for the country's agriculture to produce the products that will be demanding and competitive in the local market against foreign products.

That is why it was necessary to conduct the research and to determine how possible it is for Imereti region to increase the production of agribusiness and how competitive our products are in terms of price and quality compared to those produced abroad. It is worth noting here that we focused on the consumed goods in the tourism sector and emphasized that foreign tourists should be offered Georgian products and not goods imported from their own countries in order to taste our national product and see its benefits.

Within the framework of the internal faculty grant project at Akaki Tsereteli State University in 2018-2019, a survey was conducted for business in Imereti region, looking for ways to develop their potential. The study was to determine how much the products produced in Imereti region are consumed by the hotels of Kutaisi, Batumi and
Zaporozhye. To find out all this, we first got acquainted with samples of products produced in Imereti region and offered some food services to the hotels.

\section{Methodology of the research}

We used the following methods for the study: a field research, an office research based on complex, interdisciplinary approaches, analysis and synthesis. The joint use of these surveys allowed us to gain more comprehensive information and identify ways to solve existing problems and develop recommendations that would help Imereti region business succeed in the future.

\section{Results of the research}

The research shows that the development of agrarian business in the Imereti region is promising. At this point we

diagram 1. At what price do you buy these products on average per year? (Specify price in $\mathrm{kg} /$ )

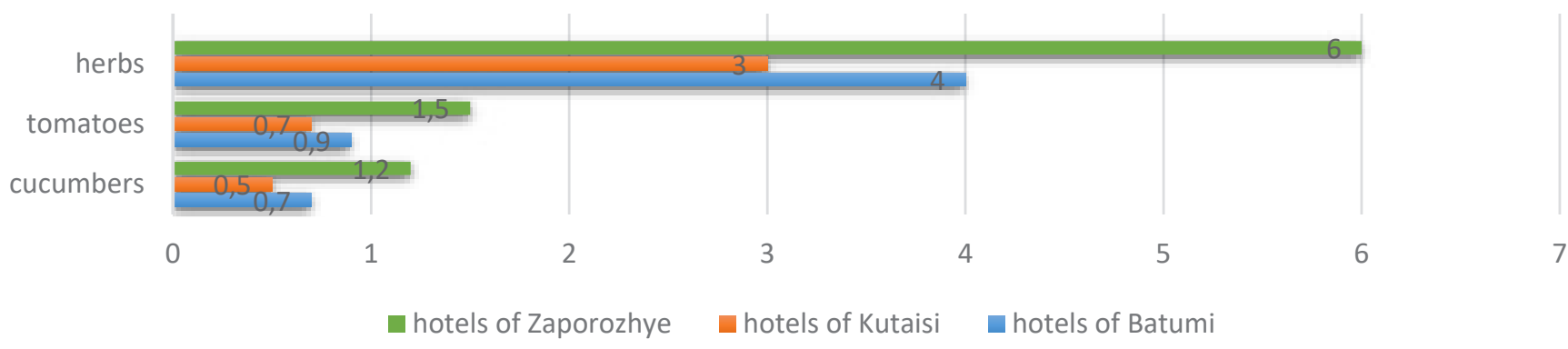

Source: The Research Results of the Project "Study of Business Development Potential for Business in Imereti Region". 2018-2019. (Akaki Tsereteli State University)

Diagram 2. Would you like to buy the products produced in Imereti Region? (cucumbers, tomatoes, herbs)

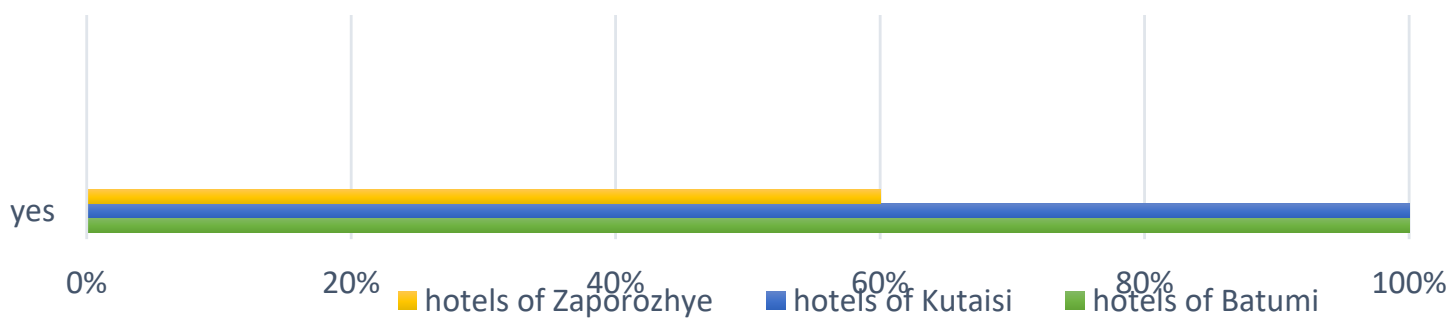

Source: The Research Results of the Project "Study of Business Development Potential for Business in Imereti Region". 2018-2019. (Akaki Tsereteli State University)

As it can be seen from the diagram, the hotel administration is ready to buy these products produced in Imereti region.

diagram 3. How much do you on average pay for cheese per year? (Specify price in $\mathrm{kg} / \$$ )

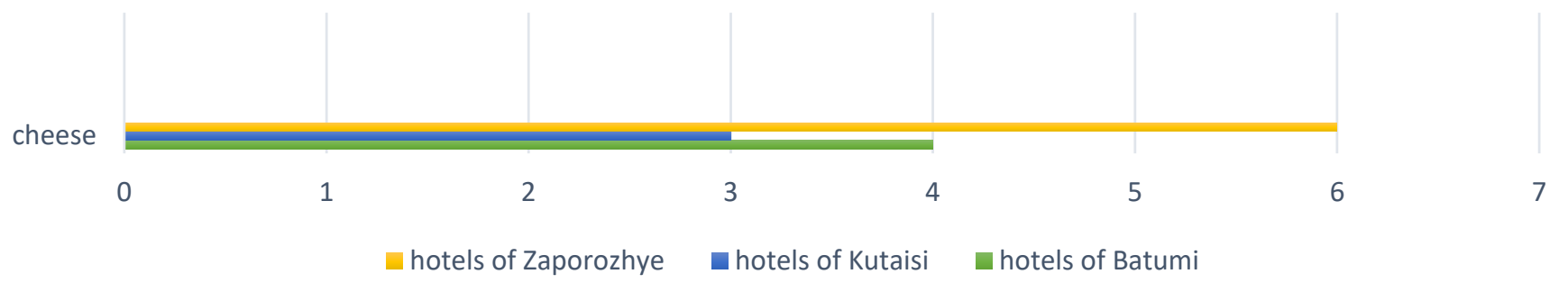

Source: The Research Results of the Project "Study of Business Development Potential for Business in Imereti Region". 2018-2019. (Akaki Tsereteli State University) 
will focus on the research held in Kutaisi (Georgia), Batumi (Georgia) and Zaporozhye (Ukraine) and identify some products (The study was conducted in 20 hotels in Kutaisi, 40 hotels in Batumi and 20 hotels in Zaporozhe). The question was asked in the following way: how much do you pay for the certain product and would you like to buy the same products produced in Imereti region?

The research has shown that various products produced in Imereti region (especially: cucumbers, tomatoes, herbs, wine, cheese, tea) are quite in demand for food services in hotel, but still the hotels in Imereti region are not adequately supplied with the production produced in Imereti region. There may be many reasons for this, but we will focus on a few of them, namely: local farmers cannot systematically supply the market with the products produced throughout the year; due to the economies of scale of production, products produced in Imereti region may be more expensive than products produced in another country; distribution links are not used properly, etc.

Business representatives pointed out that if the state had more support for the business (such as available credits, supporting new technologies, government procurement, etc.), they would be more likely to meet the needs of hotels and local needs.

\section{CONCLUSIONS AND PROPOSALS}

In conclusion, we can say that there are potential opportunities for agribusiness development in Imereti region as well as in Georgia as a whole. Agricultural products

diagram 4. Would you like to buy some cheese produced in Imereti Region?

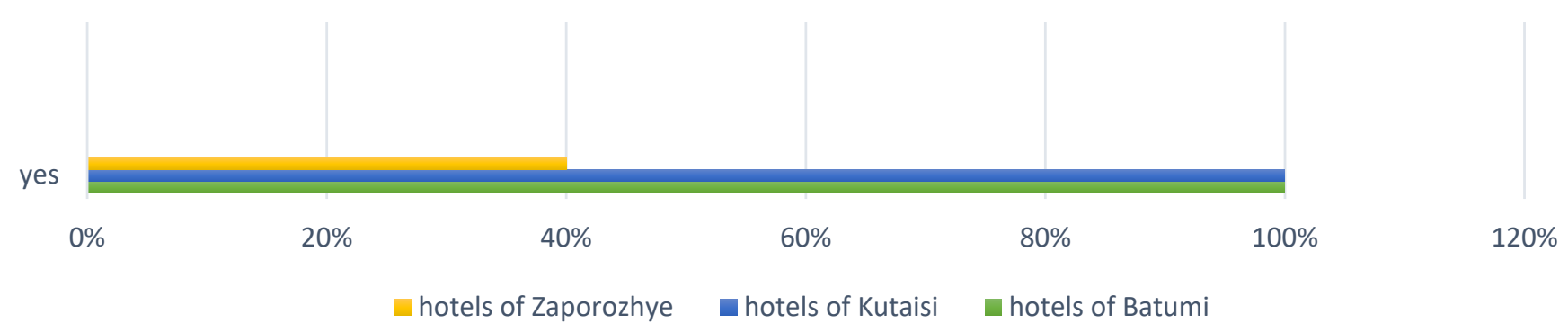

Source: The Research Results of the Project "Study of Business Development Potential for Business in Imereti Region". 2018-2019. (Akaki Tsereteli State University)

As the diagram shows, the hotel administration is ready to buy cheese produced in Imereti region.

diagram 5. How much do you on average pay for wine per year? (Specify bottle in / \$)

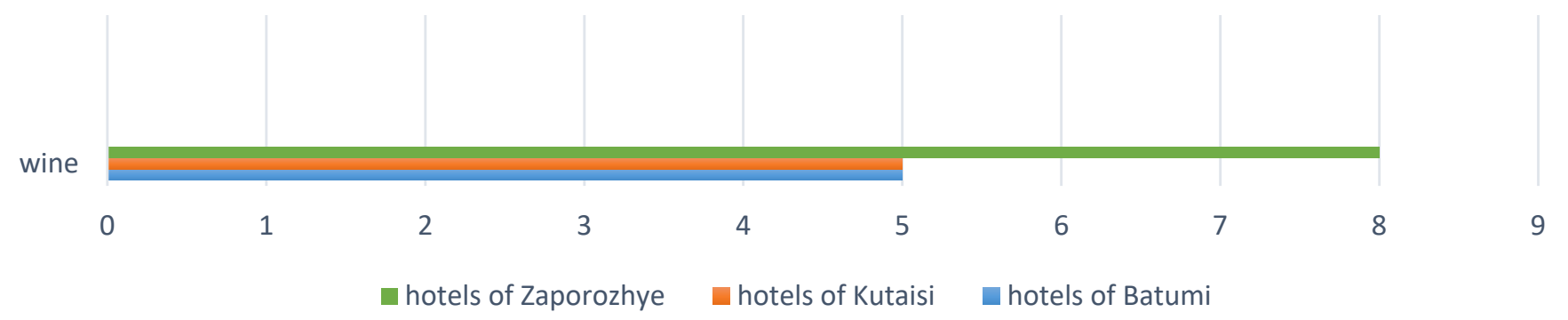

Source: The Research Results of the Project "Study of Business Development Potential for Business in Imereti Region". 2018-2019. (Akaki Tsereteli State University)

diagram 6. Would you like to buy some wine produced in Imereti Region?

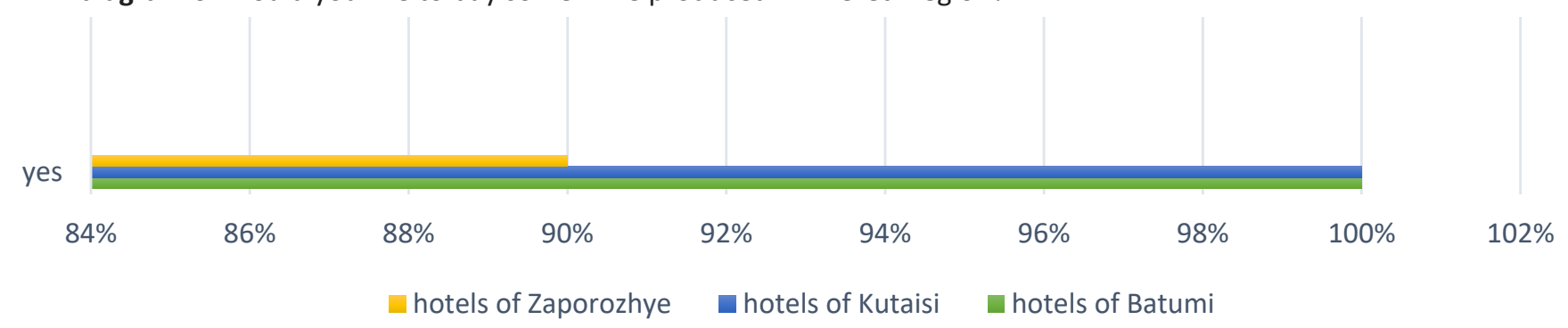

Source: The Research Results of the Project "Study of Business Development Potential for Business in Imereti Region". 2018-2019. (Akaki Tsereteli State University)

As the diagram shows, the hotel administration is ready to buy wine produced in Imereti region 
diagram 7. How much do you on average pay for tea per year? (Specify kg in / \$)

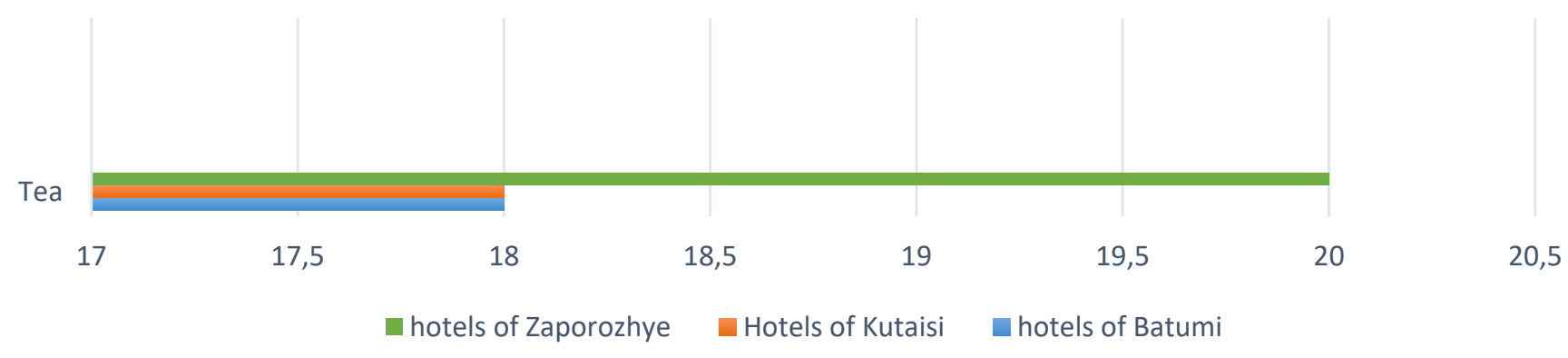

Source: The Research Results of the Project "Study of Business Development Potential for Business in Imereti Region". 2018-2019. (Akaki Tsereteli State University)

diagram 8. Would you like to buy some tea produced in Imereti Region?

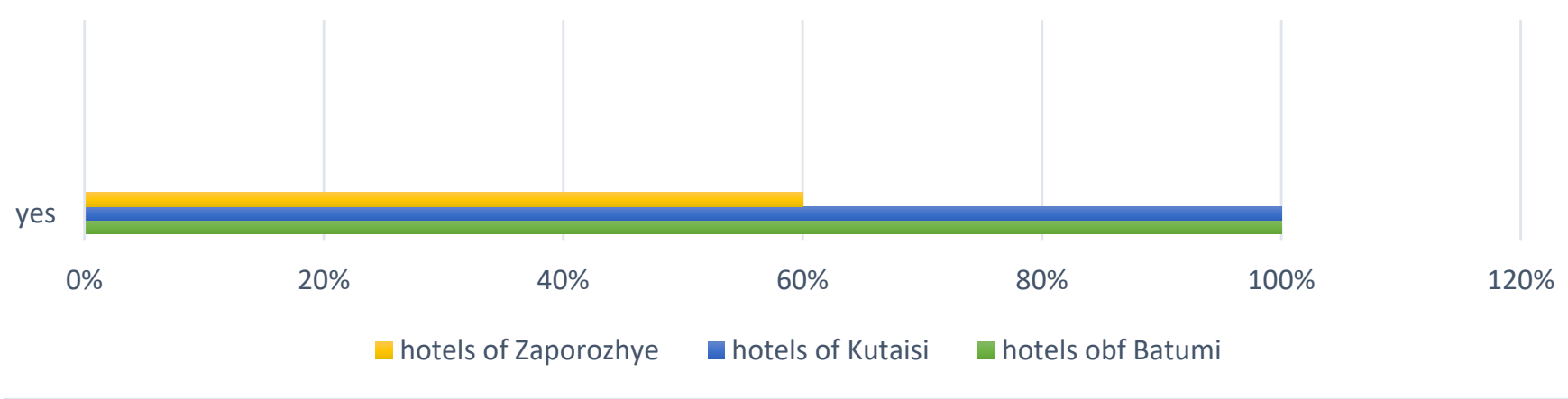

Source: The Research Results of the Project "Study of Business Development Potential for Business in Imereti Region". 2018-2019. (Akaki Tsereteli State University)

As the diagram shows, the hotel administration is ready to buy tea produced in Imereti region.

produced in Imereti region are in demand and consumers are eager to purchase these products, but in most cases, the demand exceeds the supply.

The following conclusions and proposals can be made:

1. The agricultural products produced in Imereti region are of quite high quality, well-liked and the hotels have expressed the desire to use them more in food services.

2. In order to be continuously supplied by the products by farmers, hotels need to have solid guarantees under a mutually co-operative agreement.

3. It is desirable that government-supported agribusiness development programs become more transparent and accessible to interested business entities.

4. In order to support farmers, while making purchases, it is desirable to prefer local quality products rather than cheap products.

\section{REFERENCES}

Results of the research carried out within the framework of the internal faculty grant of Akaki Tsereteli State University, Faculty of Business, Law and Social Sciences of the project Exploring Business Development Potential for Businesses in Imereti Region. (2018-2019).

Annual Report of the Ministry of Environment Protection and Agriculture of Georgia for 2019.

Tokmazishvili, M. (2018). Theoretical Dilemma of Agrarian Relations. Collection of scientific works of Tbilisi Open University. Tbilisi. Koguashvili, P., (2013). Protecting food security is the primary duty of the government. New Agrarian Georgia. Tbilisi. № 12 (32) Georgiass economic development priorities. Regional Development Program (GARF-RD) Policy Papers №2, Tbilisi 2016. 58-60. Werner, S., Scott R. Lemos Jr., Amanda McLeod, John M. Halstead, Todd Gabe, Ju-Chin Huang, Chyi Lyi Liang, Wei Shi, Lily Harris, L. \& McConnon, J. „Prospects for New England Agriculture: Farm to Fork Agricultural and resource economics review, Vol. 48 / Number 3. December 2019. 473 - 505.

Zacharias, T. P., Modeling and Simulating Price, Yield, and Production Distributions for Risk Analysis in Agriculture: Discussion, Materials of Cambridge University. 2015.

Gillespie, J. M., \& Bampasidou M. Designing agricultural economics and agribusiness undergraduate programs. Journal of Agricultural and Applied Economics 50 (3) Materials of Cambridge University. 2018. 